\title{
Optimalisasi Keberhasilan Siswa Mu'allimin Yogyakarta Dengan Aplikasi Sistem Informasi Pada Pilihan Penjurusan
}

\author{
Supriantara ${ }^{1}$ Kusrini $^{2}$, Sudarmawan ${ }^{3}$ \\ 1,2,3 Universitas Amikom Yogyakarta \\ Pasca Sarjana Teknik Informatika, Universitas Amikom Yogyakarta \\ $\underline{{ }^{1} \text { supriantara@gmail.com }}, \underline{2}$ Kusrini@ amikom.ac.id,$\underline{{ }^{3} \text { Sudarmawan@ amikom.ac.id }}$
}

\begin{abstract}
Abstrak-Peminatan penjurusan pada sekolah/madrasah dapat di kalsifikasikan berdasarkan hasil dari nilai akhir USBN, nilai akhir UNBK serta rekomendasi dari guru bimbingan konseling (BK). Peraturan pemerintah no. 64 tahun 2014 menyatakan bahawa siswa di kelas $X$ dapat masuk penjurusan baik di IPA maupun IPS, dan hal ini menjadi tantangan bagi para guru khususnya yang mengajar di bidang IPA, dimana para guru harus memiliki strategi dan model pembelajaran yang dapat mendukung terciptanya proses pembelajaran yang ideal ketika siswa memasuki penjurusan di awal kelas X SMA/Madrasah. Salah satu strategi yang dilakukan adalah dengan menggunakan aplikasi sistem informasi pada pilihan penjurusan, namun penerapannya masih perlu dioptimalkan. Pendekatan yang digunakan dalam Penelitian ini menggunakan metode diskriptif kuantitatif dengan metode pengumpulan data yang didapat dari nilai raport yang difilter menggunakan aplikasi yang sudah berjalan dan nilai ujian nasional. Kemudian hasil tersebut digunakan untuk mengambil data kelas yang memiliki proses dan metode pembelajaran yang ideal. Sehingga dari hasil tersebut dapat digunakan untuk meningkatkan keberhasilan siswa-siswa dalam melakukan pembelajaran khususnya ketika berada pada program penjurusan.
\end{abstract}

Kata kunci-Peminatan, guru, strategi, aplikasi sistem infomasi, model dan metode belajar, dan hasil belajar

\section{PENDAHULUAN}

Madrasah Muallimin merupakan Madrasah yang berbasis boarding School. Didalamnya juga mengemban misi pelajaran kepesantrenan, jenjang yang ada di mulai dari kelas 1 MTs (Madrasah Tsanawiyah setingkat dengan SMP) hingga kelas 6 MA (Madrasah Aliyah setingkat SMA). Saat perpindahan jenjang dari MTs ke MA. Unit BK (Bimbingan Konseling) sangat berperan aktif dalam kegiatan penjurusan/peminatan siswa, kegiatan penjurusan dilakukan untuk menempatkan siswa sesuai dengan bidang minat serta kompetensi yang dimiliki [1].

Tujuan penjurusan sendiri tentunya agar minat dan bakat seseorang dapat terarah dengan spesifik pada bidang ilmu tersebut yang selanjutnya dapat melanjutkan ke jenjang Selanjutnya [2]. Pihak Madrasah menginginkan adanya peningkatan siswa alumni yang di terima di perguruan tinggi Negeri, dan tentunya saat ini, masalah kegagalan studi siswa dan faktor-faktor penyebabnya menjadi topik yang menarik untuk diteliti [3].

Peraturan Menteri Pendidikan dan Kebudayaan Republik Indonesia Nomor 64 Tahun 2014 tentang Peminatan pada Pendidikan Menengah, pemilihan kelompok peminatan ini dapat dilakukan semenjak siswa mendaftar SMA/MA. Landasan yang digunakan untuk peminatan/penjurusan dapat menggunakan nilai rapor, nilai Ujian Nasional, Serta rekomendasi dari pihak guru Bimbingan dan Konseling/Konselor di SMP/MTs atau yang sederajat. Setelah melewati proses penjurusan, maka siswa dapat mengambil mata pelajaran yang sesuai dengan penjuruan dari awal semester hingga akhir semester selain itu siswa dapat mengambil mata pelajaran lintas minat. Keputusan penjuruan diambil dari hasil pemecahan masalah yang dihadapi dengan tegas. Suatu keputusan merupakan jawaban yang pasti terhadap suatu pertanyaan. Keputusan harus dapat menjawab pertanyaan tentang apa yang dibicarakan dalam hubungannya dengan perencanaan.[4]

Hasil Evaluasi dari penggunaan sistem informasi ujian berbasis komputer digunakan untuk memetakan tingkat kemampuan siswa serta keberhasilan guru dalam menerapkan metode pembelajaran yang dipakai dikelas. Pemetaan ini dibuat untuk mengukur daya serap siswa pada satu siklus sesi pembelajaran. Yang nantinya digunakan untuk memperkuat daya serap di siklus pembelajaran selanjutnya.

\section{LANDASAN TEORI}

Pendidikan berbasis teknologi merupakan sebuah kegiatan yang didalamnya terdapat proses pembelajaran menggunakan teknologi sebagai pendukungnya. [5]

Teknologi pembelajaran berfungsi sebagai penjembatan antara peserta murid dan guru, serta sebagai alat untuk memicu motivasi dari siswa dalam melakukan proses pemebelajran. [6]

Klasifikasi merupakan bagian dari prediksi, Klasifikasi sendiri dapat menentukan class atau grup dari tiap contoh data, input dari model. [7]

Structural Equation Modelling atau biasa disebut SEM merupakan teknik modelling statistik yang bersifat sangat cross-sectional, liniear dan umum. 
berbeda dengan definisi sebelumya, disebutkan SEM berkembang dan mempunyai fungsi mirip dengan regresi berganda[8], tetapi SEM menjadi suatu teknik analisis yang lebih kuat karena SEM memiliki kompetensi untuk melakukan analisa sampai level terdalam dari sebuah variabel atau model yang diteliti. Maka metode ini meruapakan sebuah metode yang mempunyai kompetensi untuk melakukan analisa serta prediksi yang lebih baik dari analisis jalur dan regresi berganda. Selain itu metode ini lebih koperehensif dalam mendeskripsikan berbagai fenomena di dalam sebuah penelitian. [9]

\section{METODE}

Penelitian ini menggunakan action research., untuk lebih jelasnya alur penelitihan action research dijelaskan pada gambar :

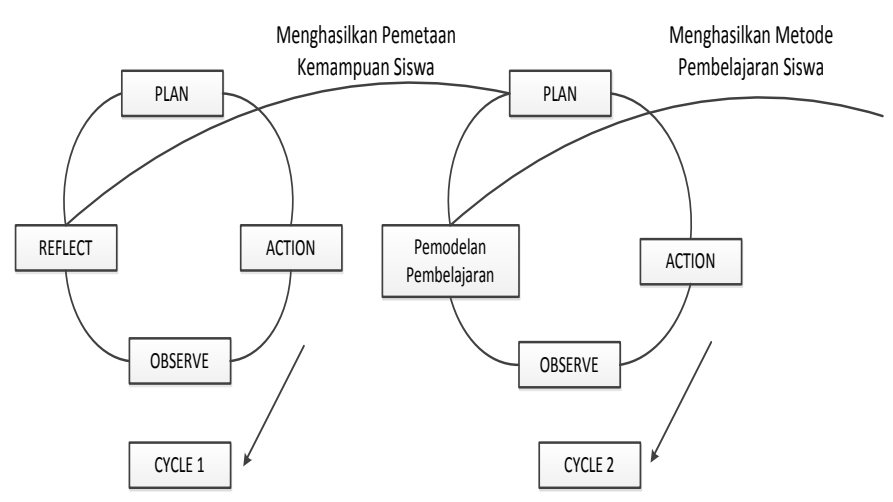

Gambar 1. Action Research

Berikut adalah penjelasan singkat dari beberapa tahapan dalam penelitian action research, adapaun rinciannya sebagai berikut:

1. Tahapan perencanaan (planning)

Tahapan ini merupakan kegiatan menyiapkan fasilitas serta sarana yang dibutuhkan dalam penelitian seperti instrumen, serta tools yang digunakan untuk menganalisa data.

2. Tahapan tindakan (action)

Terdapat kegiatan awal, inti dan penutup.

3. Kegiatan pengamatan (observing)

Tahapan ini merupakan tahapan yang berisi kegiatan mengumpulkan data berupa obeservasi maupun wawancara dengan pihak terkait.

4. Tahapan refleksi (reflecting)

Tahapan ini bersisi tindakan untuk mencatat hasil analisa data dan obeservasi, kemudian menganalisis hasil analisa data dari kompetensi siswa, serta kekurangan yang ada sebagai landasan untuk perbaikan tahap selanjutnya
Adapun Alur Penelitian ini adalah sebagai berikut :

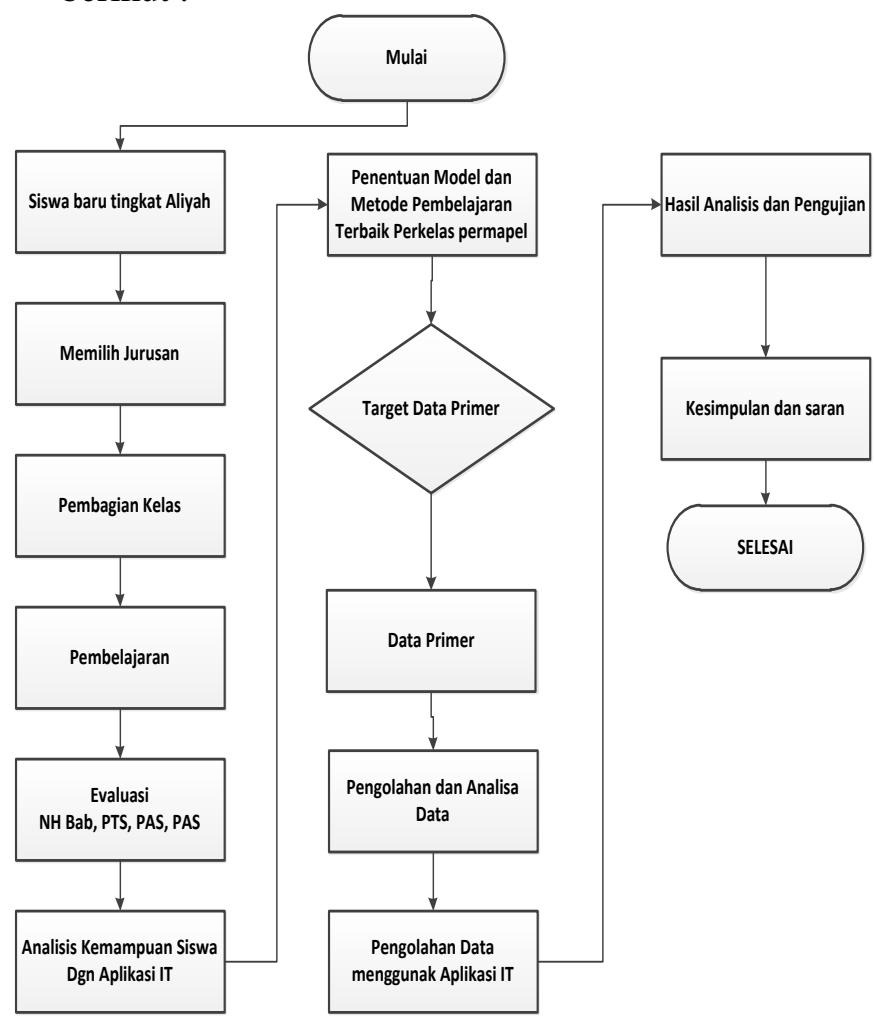

Gambar 2. Alur penelitian

IV. HASIL

Populasi yang digunakan dalam penelitian ini adalah para siswa di Madrasah Muallimin Muhammadiyah Yogyakarta. Jumlah sampel yang diambil dengan acak random sebanyak 100 orang, metode accidental sampling.

Sumber data yang digunakan di dalam penelitian ini merupakan data primer yang diperoleh langsung dari sumber penelitian.

Untuk pengumpulan data dalam penelitian ini dilakukan dengan menggunakan metode survei dengan memanfaatkan media kuesioner, dan memanfaatkan penggunaan skala likert untuk mengukur hasilnya.

Untuk analisis data yang digunakan menggunakan teknik analisis SEM (Structural Equation Model) dan bantuan perangkat SEM PLS (Analysis of Moment Structure) juga software SPSS yang bisa dijalankan di sistem operasi Windows. Perangkat ini nantinya akan digunakan untuk melakukan uji validitas dan uji reliabilitas dari kuesioner yang sudah dibuat terhadap30 siswa kelas XII IPA. 
Tabel 1. Hasi Uji validitas

\begin{tabular}{|c|c|c|c|c|}
\hline Variabel & Ftem & $\begin{array}{l}\text { Convert } \\
\text { ed Itrm- } \\
\text { Total }\end{array}$ & \begin{tabular}{|l} 
Skor \\
M Sinimal
\end{tabular} & Keterang? \\
\hline \multirow{3}{*}{ Pengalaman } & Pengl & 0,797 & 0,3 & Valid \\
\hline & leng2 & 0,748 & 0,3 & Valid \\
\hline & Peng3 & 0,772 & 0,3 & Velid \\
\hline \multirow[t]{4}{*}{ Rerumitan } & Kenml & 0,869 & 0,3 & Velid \\
\hline & $\mathrm{Kenm} 2$ & 0,562 & 0,3 & Velid \\
\hline & $\mathrm{K}$ erm 3 & 0,802 & 0,3 & Valid \\
\hline & Kerm4 & 0,616 & 0,3 & Valid \\
\hline \multirow{3}{*}{$\begin{array}{l}\text { Resesuaian } \\
\text { rugas }\end{array}$} & KesTugl & 0,411 & 0,3 & Velid \\
\hline & KesTug2 & 0,633 & 0,3 & Velid \\
\hline & KesTug3 & 0,645 & 0,3 & Valid \\
\hline \multirow{7}{*}{\begin{tabular}{|l} 
Sikap \\
pengzuna
\end{tabular}} & SikPengg1 & 0,829 & 0,3 & Valid \\
\hline & SikPengg:2 & 0,774 & 0,3 & Velid \\
\hline & Sik-Pengg33 & 0,851 & 0,3 & Velid \\
\hline & SikPengg 4 & 0,785 & 0,3 & Valid \\
\hline & SikPengg 5 & 0,816 & 0,3 & Valid \\
\hline & SikPengg 6 & 0,819 & 0,3 & Velid \\
\hline & SikPengg? & 0,518 & 0,3 & Velid \\
\hline \multirow{7}{*}{$\begin{array}{l}\text { Persepsi } \\
\text { kegunann }\end{array}$} & PersKeg1 & 0,554 & 0,3 & Valid \\
\hline & PeraXeg2 & 0,761 & 0,3 & Velid \\
\hline & PersKeg3 & 0,524 & 0,3 & Valid \\
\hline & PeraKeg4 & 0,781 & 0,3 & Valid \\
\hline & PeraKeg5 & 0,672 & 0,3 & Valid \\
\hline & PeraKeg6 & 0.544 & 0,3 & Valid \\
\hline & PeraKeg? & 0,489 & 0,3 & Velid \\
\hline \multirow{5}{*}{$\begin{array}{l}\text { Parye } \\
\text { si } \\
\text { cermud } \\
\text { phan }\end{array}$} & PerKemdl & 0,806 & 0,3 & Velid \\
\hline & PerKemd2 & 0,908 & 0,3 & Valid \\
\hline & PerKemd3 & 0,920 & 0,3 & Valid \\
\hline & PerKemd4 & 0,914 & 0,3 & Valid \\
\hline & PerKemd5 & 0,900 & 0,3 & Valid \\
\hline \multirow{4}{*}{ Sinat perilaku } & MinPerl & 0,655 & 0,3 & \begin{tabular}{|l|l|} 
Velid \\
\end{tabular} \\
\hline & MinPer2 & 0,816 & 0,3 & Valid \\
\hline & MinPer3 & 0,800 & 0,3 & Velid \\
\hline & MinPer4 & 0,866 & 0,3 & \begin{tabular}{|l|l|} 
Velid \\
\end{tabular} \\
\hline \multirow{5}{*}{$\begin{array}{l}\text { Penggunaan } \\
\text { myatz }\end{array}$} & PengNyal & 0,374 & 0,3 & Valid \\
\hline & PengNya2 & 0,597 & 0,3 & Valid \\
\hline & PengNya3 & 0,563 & 0,3 & Valid \\
\hline & PengNya4 & 0,578 & 0,3 & Velid \\
\hline & PengNya5 & 0,406 & 0,3 & \begin{tabular}{|l|l|} 
Valid \\
\end{tabular} \\
\hline
\end{tabular}

Hasil uji reliabilitas dari 30 responden menghasilkan bahwa variabel pengalaman memiliki nilai 0,881 ,Nilai kerumitan 0,846 , Nilai kesesuaian dari tugas sebesar 0,731 ,sikap dari pengguna sebesar 0,921, dan persepsi dari kegunaan memiliki nilai 0,847 , persepsi kemudahan memiliki nilai 0,960 , minat dari perilaku senilai 0,903, penggunaan nyata sebesar 0,724.Dari hasil tersebut dapat disimpulkan bahwa tindakan dalam proses pembelajaran yang sudah dilakukan pengajar memiliki efek yang cukup baik.
Dari Hasil tes tersebut menunjukkan bahwa siswa menunjukkan peningkatan hasil belajar. dari rangkaian penelitian yang telah dilakukan, penelitian ini Beerhasil menemukan bahwa penggunaan metode dalam pembelajran pada siswa memiliki dampak yang positif terhadap peningkatan hasil Belajar siswa di Mu'allimiin Yogyakarta. Beerikut hasil prestasi Belajar siswa Mu'allimiin Yogyakarta setelah dilakukan perubahan-perubahan metode Belajar yang telah dilakukan oleh para guru di Mu'allimiin Yogyakarta.

Gambaran perbedaan di atas dapat diperjelas dengan gambar grafik antara prestasi nilai rapor kelas VI IPA sebelum penerapan metode pembelajran dan sesudah penerapan metode pembelajran

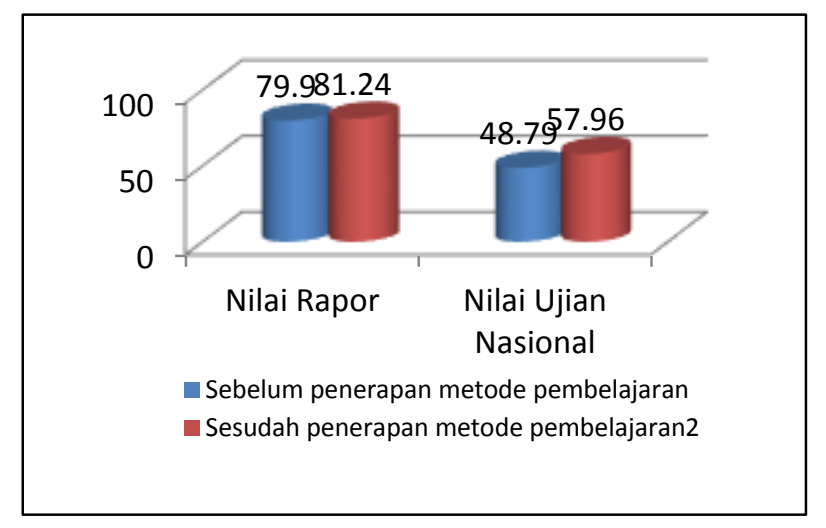

Gambar 3. Peningkatan Prestasi Belajar

Berdasarkan gambar di atas, terlihat bahwa sebelum penerapan metode dan model pembelajaran diperoleh nilai rata-rata rapor pada siswa kelas VI IPA yaitu seBeesar 79,9 yang mengalami peningkatan menjadi sebesar 81,24 sesudah penerapan metode pembelajaran. Dengan demikian, dilaksanakan tindakan metode dan model pembelajaran yang dilakukan oleh para guru Mu'allimiin Yogyakarta mampu meningkatkan prestasi belajar siswa yang dapat dibuktikan dengan naiknya nilai rapor dan ujian nasional para siswa Mu'allimiin Yogyakarta.

Bukti peningkatan ini juga ditunjukkan dengan jumlah lulusan dari Mu'allimiin Yogyakarta yang diterima di perguruan tinggi negeri yang jumlahnya meningkat. Beerdasarkan hasil penelitian yang telah dilakukan diperoleh bahwa jumlah lulusan dari Mu'allimiin Yogyakarta yang diterima di perguruan tinggi negeri sebelum penerapan metode pembelajaran terdapat 17 orang. Hal ini berbeda sesudah penerapan metode pembelajaran, dimana jumlah siswa Mu'allimiin Yogyakarta yang bisa diterima 
di perguruan tinggi negeri jumlahnya meningkat menjadi sebanyak 26 orang. Hal ini menjelaskan bahwa penerapan metode pembelajaran akan menghasilkan prestasi belajar yang lebih baik jika dibandingkan dengan tidak dilakukannya metode dan model pembelajaran yang tepat dalam mengajar siswa.

\section{KESIMPULAN}

Berdasarkan analisis hasil penelitian pada bab sebelumnya, maka dapat diambil beberapa kesimpulan sebagai berikut.

1. Metode dan Model yang diajarkan oleh guru akan terlihat ketika para siswa melaksankan ujian berbasis komputer, pengaruh terhadap persepsi kemudahan dalam pelaksanaan ujian berbasis komputer. Sedangkan kerumitan dalam menjawab soal ujian menggunakan komputer berpengaruh terhadap persepsi kegunaan dan persepsi kemudahan dalam pelaksanaan ujian berbasis komputer yang diikuti siswa.

2. Pengaruh dari hasil data yang telah diolah dengan mixrosoft excek untuk menentukan keberhasilan metode dan model yang diajarkan oleh guru kepada siswa dalam memetakan kerumitan materi yang diajarkann sehingga dapat melakukan evaluasi metode dan model yang diajarkan kedepan perkelasnya nanti. Sehingga pemilihan penjurusan yang dipilih oleh para siswa tidak menjadi penghalang guru dalam mengajarkan materinya. Hal ini dikarenakan pemilihan jurusan terbatas pada permintaan minat saja dari para siswa.

3. Upaya peningkatan prestasi belajar siswa tidak terlepas dari berbagai faktor yang mempengaruhinya, beberapa hal yang telah dilakukan oleh para guru Mu'allimiin Yogyakarta dalam meningkatkan prestasi belajar siswa diantanya adalah : Mengelompokkan nilai harian atau ulangan per kelas dan mengelompokkan siswa dari tiga kelas menjadi satu kelas yang dipisahkan menjadi tiga kelompok nilai yaitu nilai rendah, nilai sedang dan nilai tinggi pada saat mendekati ujian nasional akan dilakukan dan dengan memberi pelajaran tambahan disore hari dengan menggunakan data yang telah didapat dari guru yang mengajar.

\section{DAFTAR PUSTAKA}

[1] D. N. Handayani, F. N. Hakim, dan A. Solechan, "Sistem Pendukung Keputusan Untuk Pemilihan Jurusan Menggunakan Fuzzy Multiple Atribute Decision Making Dengan Metode Simple Additive Weighting Studi Kasus Pada Sma Islam Sultan Agung 1 Semarang," J. Transform., vol. 11, no. 2, hal. 69, 2014.

[2] dkk Rizky Ade Putranto, "Perbandingan Analisis Klasifikasi Antara Decision Tree dan Support Vector Machine Muticlass Untuk Penentu Jurusan Pada Siswa SMA," Gausian, vol. 4, no. Data Mining, hal. 1007-1016, 2015.

[3] Khafiizh Hastuti, "Analisis Komparasi Algoritma Klasifikasi Data Mining Untuk Prediksi Mahasiswa Non Aktif," Semin. Nas. Teknol. Inf. Komun. Terap. 2012 (Semantik, vol. 14, no. 1, hal. 241-249, 1994.

[4] A. Ristyawan dan B. V. Indriyono, "Penerapan Metode Simple Additive Weighting (SAW) untuk Pengambilan Keputusan Pemberian Upah Karyawan," Semin. Nas. Teknol. Inf. dan Multimed. 2015, hal. 6-8, 2015.

[5] D. Setiawan, "PERSPEKTIF E-LEARNING DOSEN PROGRAM STUDI SISTEM INFROMASI UNIPMA," Res. J. Comput. Inf. Syst. \&technologymanagement, vol. 1, no. 2, hal. 1-6, 2018.

[6] D. Setiawan, I. Arifin, dan R. Ardianto, "Implementasi Pengembangan Sistem Media Pembelajaran Pengenalan Komputer," INTENSIF, vol. 2, no. 2, hal. 127-135, Mei 2018.

[7] Muchlis dan Taufiqurochman, “Analisa pencapaian hafalan al- qur'an dalam camptahfizh dengan algoritma c.45 dan penerapannya," Semnastek Umj 2017, no. November, hal. 1-2, 2017.

[8] J. Sarwono, "Pengertian Dasar Structural Equation Modeling ( Sem )," J. Ilm. Manaj. Bisnis, vol. 10, no. 3, hal. 173-182, 2010.

[9] D. A. Miftahul Ulum, IMade Tirta, "ANALISIS STRUCTURAL EQUATIONMODELING ( SEM ) UNTUK SAMPEL KECIL DENGAN PENDEKATAN PARTIAL LEAST SQUARE ( PLS ) ( STRUCTURALEQUATION MODELING ( SEM ) ANALYSIS FOR 
SMALL SAMPLE WITH PARTIAL LEAST

SQUARE ) 1 Pendahuluan," Pros. Semin. Nas.

Mat. Univ. Jember, no. November, hal. 1-15, 2014. 